\title{
Triage tools: a cautious (and critical) view towards their use in old patients
}

\author{
Mireia Puig-Campmany ${ }^{1,2,3}$ (1) Marta Blázquez-Andión ${ }^{1,2,3} \cdot$ Josep Ris-Romeu 1,2,3
}

Published online: 5 October 2021

(c) The Author(s), under exclusive licence to European Geriatric Medicine Society 2021

The number of older people, especially those with complex conditions, has increased significantly in emergency departments (ED). Accordingly, it is essential to transform $\mathrm{ED}$, both structurally and from an organizational point of view, by implementing models of care tailored to the specific requirements of this population. Many successful experiences have shown to substantially improve quality of care and increase patient satisfaction and efficiency in this setting [1-4]. The interpretation and use of the triage process for the older adult in the ED are undoubtedly the first major difference with respect to younger people [5-8]. It has been described repeatedly how current triage methods produce inadequately low results in older patients [9-11]. This risk of underestimation of urgency translates into longer waiting times and a higher risk of adverse outcomes due to the delay [12-14]. Therefore, despite the usefulness of triage tools, we recognize inconsistencies and notable room for improvement that force us to be cautious in their interpretation and to consider their critical review.

Triage is a fundamental tool in the practice of emergency medicine. It is used to prioritize patients when the needs for care exceed the available resources [15]. Its objective is to manage the delay in patient care based on clinical urgency. It should quickly detect which patients present potentially lethal situations or those with a higher risk of morbidity when not treated immediately, thus reducing the possible negative impact of a delay in treatment [16]. Since the triage process itself implies that not all needs are met immediately, it is essential to ensure that triage methods meet their objectives and should, therefore, also be evaluated against specific

Mireia Puig-Campmany

mpuigc@santpau.cat

1 Emergency Department, Hospital de la Santa Creu i Sant Pau, Barcelona, Catalonia, Spain

2 Universitat Autònoma de Barcelona, Barcelona, Spain

3 IIB Sant Pau Research, Barcelona, Spain populations, as Lucke et al. do in the older adult group in the present issue [17].

Triage started to become widespread 30 years ago in emergency departments, and since then, several standardized triage tools have been developed and implemented [18]. The most widely used are the Australasian Triage Scale (ATS), the Canadian Triage and Acuity Scale (CTAS), the Emergency Severity Index (ESI), the Manchester Triage Scale (MTS), and the South African Triage Scale (SATS) [19]. They all have common aspects: development through expert group consensus; use of a 5-level classification scheme; set maximum delay targets per triage level; and universally rely on some level of subjectivity on the part of the individuals performing the triage. Despite these common characteristics, they differ in that some are based on the consultation reason and symptoms that patients report on arrival to the ED and others are based on physiology and vital signs.

Several studies have examined the usefulness of different triage tools in the general population and the aged [19-21]. However, the main difficulty of these studies is to establish the gold standard for their evaluation, since there is no consensus [22]. Thus, studies are mostly based on objective measures, which, therefore, have limitations, such as sensitivity and specificity in the detection of a specific urgent process (sepsis, acute coronary syndrome, pulmonary embolism); the detection of patients at high risk of death (during ED stay, during hospital admission or 7 days after discharge); or the detection of those requiring admission to the ICU or emergency surgery; or the identification of those who will require hospital admission [22]. These indicators, although approximating an answer to the effectiveness and safety of triage, are probably not the most appropriate ones. In other words, they do not offer a clear answer on whether the tool has effectively discriminated those patients who should be treated as a priority: a high priority level does not always relate to a serious condition, nor do all potentially lethal conditions require urgent priority care on arrival. In addition, the different standardized triage tools show 
variable sensitivity when studying different populations (children, young adults and older adults, medical emergencies, and surgical emergencies). Specifically, sensitivity is very low for severe sepsis (36-74\%) or pulmonary embolism (54\%) and increases for other conditions, such as ST-elevation myocardial infarction (44-85\%) and non-ST segment elevation myocardial infarction (56-92\%) [11, 19, 21]. The prediction of ICU admission ranges from 58 to $100 \%$ and the prediction of the need for life-saving surgery ranges from 77 to $98 \%$ [19]. Even more striking is that more than $20 \%$ of the patients who died after emergency care were not designated as having a high level of emergency [19].

Relevant to geriatric medicine is the fact that all triage methods show, in older adults, lower levels of efficacy than in the global population [9-11]. In consequence, old patients are at greater risk of being assigned an inappropriately low triage level, which translates into longer waiting times and a higher risk of adverse outcomes [12-14]. The poorer performance of traditional triage tools in the older population, which underestimate the urgency [23, 24], is often explained by a high frequency of atypical presentations of acute conditions, due to associated factors, such as polypharmacy, delirium or dementia that may cloud the clinical presentation of diseases [25], by the non-inclusion in scores of agecorrection factors of vital signs, and by ageism, which can also contribute to poor care and lack of compliance with evidence-based practices [26]. Many studies suggest that the urgency level and severity of the emergency process in the older patient are closely related to his or her previous situation (presence of concomitant diseases, recent admissions, recent ED visits, polypharmacy) [27, 28]. However, these data are not part of any triage system.

On the other hand, behavior of the triage tools is very inconsistent when faced with non-specific situations or with no signs of localization. In the old adult it is not unusual to obtain triage results described as malaise, weakness, fatigue... or categorized as "unable to return home". These non-specific designations usually translate into less urgent categories. However, in older patients, they are associated with a high frequency of adverse outcomes (mortality during the stay and after discharge from the ED, admission rate), higher than that of other consultation reasons classified at the same triage level [29-35].

The work included in this issue by Lucke et al. [17] aims to examine the characteristics of older patients seen in the ED who are classified as "sick adult" with the Manchester Triage System (MTS), by reviewing the different mortality and admission rates at different urgency levels for this category. The authors conclude that older patients are most often assigned the "adult unwell" presentation flowchart when using the MTS, and that patients in this category have the highest nontraumatic mortality and hospital admission rates compared with other presenting complaints. The authors' results are relevant and aligned with similar work performed on other triage scales.

Noting the various limitations of standard triage tools for the older adults, some experts recommend combining conventional triage with frailty assessment [36-38] using simple scales that can be applied by non-expert trained staff. Proper use of both tools could minimize the defects detected and improve triage and prediction of early mortality in older patients $[39,40]$. However, geriatric screening tools are prognostic tools for medium- and long-term adverse outcomes, whereas triage tools are primarily designed to assign clinical care priority [16]. Seeking their complementarity may be a useful strategy, but it is not well systematized or validated at present.

In conclusion, triage is a fundamental procedure in hospital EDs; however, there is currently no tool that has been shown to be sufficiently safe and effective in older persons [41]. Emergency departments should take this into account and set up triage and post-triage waiting time monitoring systems that consider these limitations. Perhaps the best solution would be creating new triage tools, based on artificial intelligence, that instantly integrate the patient's previous health data records on comorbidities, frailty assessment, previous ED or hospital admissions, with classic data obtained from triage systems (based on the reason for consultation or vital signs on arrival) and all combined with information on ED overcrowding [42-46]. In any case, it is necessary to look for the best tool, based on clinical research, technology and greater knowledge, but in the meantime, we must be cautious when performing uncorrected triage in emergency care of our older patients.

Author contributions All authors have contributed to drafting and revising the manuscript.

Funding Not applicable.

Availability of data and materials Not applicable.

Code availability Not applicable.

\section{Declarations}

Conflict of interest Authors declare to have no conflict of interest.

Ethical approval Not applicable.

Informed consent No patients or their data have been used in this work.

\section{References}

1. Conroy SP, Ansari K, Williams M et al (2014) A controlled evaluation of comprehensive geriatric assessment in the 
emergency department: the "Emergency Frailty Unit." Age Ageing 43(1):109-114. https://doi.org/10.1093/ageing/aft087

2. Puig Campmany M, Ris Romeu J, Blázquez Andión M, Benito VS (2019) Development of a comprehensive, multidisciplinary program of care for frailty in an emergency department. Eur Geriatr Med 10(1):37-46. https://doi.org/10.1007/s41999-018-0151-2

3. Brown CJ, Kennedy RE, Lo AX, Williams CP, Sawyer P (2016) Impact of emergency department visits and hospitalization on mobility among community-dwelling older adults. Am J Med 129(1124):e9-e15. https://doi.org/10.1016/j.amjmed.2016.05.016

4. Aldeen AZ, Mark Courtney D, Lindquist LA, Dresden SM, Gravenor SJ (2014) Geriatric emergency department innovations: preliminary data for the geriatric nurse liaison model. J Am Geriatr Soc 62:178-1785. https://doi.org/10.1111/jgs.12979

5. Rosenberg MS, Carpenter CR et al (2014) The geriatrics emergency department guidelines. Ann Emerg Med 63(5):e5-e25. https://doi.org/10.1016/S0196-0644(14)00290-X

6. Rosenberg M, Rosenberg L (2016) The geriatric emergency department. Emerg Med Clin N Am 34:629-648. https://doi.org/ 10.1111/j.1532-5415.2008.01780.x

7. Burton JH, Young J, Bernier CA (2014) The geriatric ED: structure, patient care, and considerations for the emergency department geriatric unit. Int J Gerontol 8(2):56-59. https://doi.org/10. 1016/j.ijge.2014.01.002

8. Magidson PD, Carpenter CR, Bambach K et al (2021) Chronic brain failure. Emerg Med Clin N Am 39:307-322. https://doi.org/ 10.1016/j.emc.2021.01.008

9. Brouns SHA, Mignot-Evers L, Derkx F, Lambooij SL, Dieleman JP, Haak HR (2019) Performance of the Manchester triage system in older emergency department patients: a retrospective cohort study. BMC Emerg Med 19(1):1-11. https://doi.org/10.1186/ s12873-018-0217-y

10. Baumann MR, Strout TD (2007) Triage of geriatric patients in the emergency department: validity and survival with the emergency severity index. Ann Emerg Med 49(2):234-240. https://doi.org/ 10.1016/j.annemergmed.2006.04.011

11. Zachariasse JM, Seiger N, Rood PPM et al (2017) Validity of the Manchester triage system in emergency care: a prospective observational study. PLoS ONE 12(2):1-14. https://doi.org/10. 1371/journal.pone.0170811

12. Grossmann FF, Zumbrunn T, Frauchiger A, Delport K, Bingisser R, Nickel CH (2012) At risk of undertriage? Testing the performance and accuracy of the emergency severity index in older emergency department patients. Ann Emerg Med 60(3):317-325. https://doi.org/10.1016/j.annemergmed.2011.12.013

13. Alshibani A, Alharbi M, Conroy S (2021) Under-triage of older trauma patients in prehospital care: a systematic review. Eur Geriatr Med. https://doi.org/10.1007/s41999-021-00512-5

14. Hendin A, Eagles D, Myers V, Stiell IG (2018) Characteristics and outcomes of older emergency department patients assigned a low acuity triage score. Can J Emerg Med 20(5):762-769. https://doi. org/10.1017/cem.2018.17

15. Iserson KV, Moskop JC (2007) Triage in medicine, part I: concept, history, and types. Ann Emerg Med 49(3):275-281. https://doi. org/10.1016/j.annemergmed.2006.05.019

16. Blomaard LC, Speksnijder C, Lucke JA et al (2020) Geriatric screening, triage urgency, and 30-day mortality in older emergency department patients. J Am Geriatr Soc 68(8):1755-1762. https://doi.org/10.1111/jgs.16427

17. Lucke JA, Mooijaart SP, Conroy S et al (2021) Mortality risk for different presenting complaints amongst older patients assessed with the Manchester triage system. Eur Geriatr Med. https://doi. org/10.1007/s41999-021-00568-3

18. Hinson JS, Martinez DA, Cabral S et al (2018) Triage performance in emergency medicine: a systematic review. Ann Emerg Med. https://doi.org/10.1016/j.annemergmed.2018.09.022
19. Hinson JS, Martinez DA, Cabral S et al (2019) Triage performance in emergency medicine: a systematic review. Ann Emerg Med 74(1):140-152. https://doi.org/10.1016/j.annemergmed. 2018.09.022

20. Farrohknia N, Castrén M, Ehrenberg A et al (2011) Emergency department triage scales and their components: a systematic review of the scientific evidence. Scand J Trauma Resusc Emerg Med 19:1-13. https://doi.org/10.1186/1757-7241-19-42

21. Gräff I, Goldschmidt B, Glien P et al (2014) The German version of the Manchester triage system and its quality criteriafirst assessment of validity and reliability. PLoS ONE 9(2):111. https://doi.org/10.1371/journal.pone.0088995

22. Kuriyama A, Urushidani S, Nakayama T (2017) Five-level emergency triage systems: variation in assessment of validity. Emerg Med J 34(11):703-710. https://doi.org/10.1136/emerm ed-2016-206295

23. McGarry M, Shenvi CL (2021) Identification of acute coronary syndrome in the elderly. Emerg Med Clin N Am 39(2):339-346

24. Clare D, Zink KL (2021) Geriatric trauma. Emerg Med Clin N Am 39(2):257-271. https://doi.org/10.1016/j.emc.2021.01.002

25. Shenvi CL, Platts-Mills TF (2019) Managing the elderly emergency department patient. Ann Emerg Med 73(3):302-307. https://doi.org/10.1016/j.annemergmed.2018.08.426

26. Pham KD, Lim FA (2020) The impact of geriatric-specific triage tools among older adults in the emergency department. Crit Care Nurs Q 43(1):39-57. https://doi.org/10.1097/CNQ.00000 00000000290

27. Hofman SE, Lucke JA, Heim N et al (2016) Prediction of 90-day mortality in older patients after discharge from an emergency department: a retrospective follow-up study. BMC Emerg Med 16(1):1-10. https://doi.org/10.1186/s12873-016-0090-5

28. Dugas AF, Kirsch TD, Toerper M et al (2016) An electronic emergency triage system to improve patient distribution by critical outcomes. J Emerg Med 50(6):910-918. https://doi.org/10. 1016/j.jemermed.2016.02.026

29. Rutschmann OT, Chevalley T, Zumwald C, Luthy C, Vermeulen B, Sarasin FP (2005) Pitfalls in the emergency department triage of frail elderly patients without specific complaints. Swiss Med Wkly 135(9-10):145-150. https://doi.org/10.4414/SMW. 2005.10888

30. Bhalla MC, Wilber ST, Stiffler KA, Ondrejka JE, Gerson LW (2014) Weakness and fatigue in older ED patients in the United States. Am J Emerg Med 32(11):1395-1398. https://doi.org/10. 1016/j.ajem.2014.08.027

31. Brutschin V, Kogej M, Schacher S, Berger M, Gräff I (2021) The presentational flow chart "unwell adult" of the Manchester triage system-curse or blessing? PLoS ONE 16(6 June):1-15. https://doi.org/10.1371/journal.pone.0252730

32. Djärv T, Castrén M, Martenson L, Kurland L (2015) Decreased general condition in the emergency department: high in-hospital mortality and a broad range of discharge diagnoses. Eur J Emerg Med 22(4):241-246. https://doi.org/10.1097/MEJ.0000000000 000164

33. Karakoumis J, Nickel CH, Kirsch M et al (2015) Emergency presentations with nonspecific complaints-the burden of morbidity and the spectrum of underlying disease: nonspecific complaints and underlying disease. Medicine (United States) 94(26):1-7. https://doi.org/10.1097/MD.0000000000000840

34. Kemp K, Mertanen R, Lääperi M, Niemi-Murola L, Lehtonen L, Castren M (2020) Nonspecific complaints in the emergency department-a systematic review. Scand J Trauma Resusc Emerg Med 28(1):1-12. https://doi.org/10.1186/ s13049-020-0699-y

35. Malinovska A, Nickel CH, Bingisser R (2018) Trajectories of survival in patients with nonspecific complaints. Eur J Intern Med 55(July):e17-e18. https://doi.org/10.1016/j.ejim.2018.06.020 
36. Cousins G, Bennett Z, Dillon G, Smith SM, Galvin R (2013) Adverse outcomes in older adults attending emergency department: systematic review and meta-analysis of the Triage Risk Stratification Tool. Eur J Emerg Med 20(4):230-239. https://doi. org/10.1097/MEJ.0b013e3283606ba6

37. Carpenter CR, Shelton E, Fowler S et al (2015) Risk factors and screening instruments to predict adverse outcomes for undifferentiated older emergency department patients: a systematic review and meta-analysis. Acad Emerg Med 22(1):1-21. https://doi.org/ 10.1111/acem.12569

38. Mccusker J, Verdon J, Vadeboncoeur A et al (2012) The elderfriendly emergency department assessment tool: development of a quality assessment tool for emergency department-based geriatric care. J Am Geriatr Soc 60:1534-1539. https://doi.org/10.1111/j. 1532-5415.2012.04058.x

39. Romero-Ortuno R, Wallis S, Biram R, Keevil V (2016) Clinical frailty adds to acute illness severity in predicting mortality in hospitalized older adults: an observational study. Eur J Intern Med 35:24-34. https://doi.org/10.1016/j.ejim.2016.08.033

40. de Gelder J, Lucke JA, Blomaard LC et al (2018) Optimization of the APOP screener to predict functional decline or mortality in older emergency department patients: cross-validation in four prospective cohorts. Exp Gerontol 110(January):253-259. https:// doi.org/10.1016/j.exger.2018.06.015

41. Rivero-Santana A, Del Pino-Sedeño T, Ramallo-Fariña Y, Vergara I, Serrano-Aguilar P (2017) Usefulness of scoring risk for adverse outcomes in older patients with the Identification of Seniors at Risk scale and the Triage Risk Screening Tool: a meta-analysis. Emergencias 29:49-60
42. Cresswell K, Callaghan M, Khan S, Sheikh Z, Mozaffar H, Sheikh A (2020) Investigating the use of data-driven artificial intelligence in computerised decision support systems for health and social care: a systematic review. Health Informatics J 26(3):2138-2147. https://doi.org/10.1177/1460458219900452

43. Kareemi H, Vaillancourt C, Rosenberg H, Fournier K, Yadav K (2021) Machine learning versus usual care for diagnostic and prognostic prediction in the emergency department: a systematic review. Acad Emerg Med. https://doi.org/10.1111/acem.14190

44. Salman OH, Taha Z, Alsabah MQ, Hussein YS, Mohammed AS, Aal-Nouman M (2021) A review on utilizing machine learning technology in the fields of electronic emergency triage and patient priority systems in telemedicine: coherent taxonomy, motivations, open research challenges and recommendations for intelligent future work. Comput Methods Programs Biomed 209:106357. https://doi.org/10.1016/j.cmpb.2021.106357

45. Shafaf N, Malek H (2019) Applications of machine learning approaches in emergency medicine; a review article. Arch Acad Emerg Med 7(1):1-9. https://doi.org/10.22037/aaem.v7i1.410

46. Weisberg EM, Chu LC, Fishman EK (2020) The first use of artificial intelligence (AI) in the ER: triage not diagnosis. Emerg Radiol 27(4):361-366. https://doi.org/10.1007/s10140-020-01773-6

Publisher's Note Springer Nature remains neutral with regard to jurisdictional claims in published maps and institutional affiliations. 